\title{
Readiness of workers for a new economy in condition of systemic changes (man - technologies - economy)
}

\author{
Viktoria Kompaniets $^{1{ }^{*}}$, Viktoria Polevaya $^{2}$, Elena Poliakova $^{1}$, and Elena Shramenko ${ }^{1}$ \\ ${ }^{1}$ Ukrainian State University of Railway Transport, Department of Economics and Management of \\ Industrial and Commercial Business, Feuerbach Sq., 7, Kharkiv, 61050, Ukraine \\ ${ }^{2}$ Kharkiv International Airport, Financial Analytics Service OOO «New Systems AM», Romashkin \\ St. 1, Kharkiv, 61031, Ukraine
}

\begin{abstract}
The article analyses and systematizes requirements set to workers in the conditions of a new economy. It has been proven that a gap exists between those requirements and real skills that young people develop under the influence of information technologies and of modern society culture. A conceptual authors' vision of the educational system development is proposed. Principles of providing a lifetime economic support for the educational system have been singled out.
\end{abstract}

\section{Introduction}

The early 21 st century heralded tectonic shifts in the culture, economy, technologies, politics, and, accordingly, in man himself. A new economy is dominated by intellectual resources, hi-tech and information - including digital - technologies. That economy imposes new requirements upon future workers [1-8].

But, as research demonstrates [9-16], today there is a problem of inconsistency between requirements set to a worker by the labour market and those values (motivation), skills and knowledge which develop in a modern man under the influence of culture, education and technologies. However, this problem has not been sufficiently recognized yet. At the same time, for those countries where the existing inconsistency is recognized, the lack of coordination between the state, employers, educational system and society as a whole with respect to requirements to the preparation of workers for the new economy and to adequate educational models remains a significant problem, the ILO (International Labour Organization) experts emphasize.

\section{Basic material}

By analyzing surveys and research [1-8] several trends may be identified in requirements that are imposed upon workers in the conditions of a new economy.

The first trend manifests itself in that employees shift their requirements towards such personal qualities of new workers which are defined by value-motivational personality

* Corresponding author: victorya.kom.ek@gmail.com 
nucleus and by relevant skills (honesty, responsibility, empathy, communicative skills, etc.). In this complex world where technical development, including the one which produces enormous information flows, has begun to rapidly outpace human abilities and a humane, cultural development of the society, it is these values that ever more define the future of countries and civilizations, and of the world as a whole.

Thus, the founder and Executive Chairman of the World Economic Forum K. Schwab believes that one of the biggest threats of the fourth industrial revolution is robotization of humanity and destruction of values and traditional meanings of life [2, p. 136]. In his opinion, a key focus needs to be placed on values in order to direct benefits engendered by new technologies towards the development of the entire society and of human identity, as well as to minimize risks [2, p. 135]. Cooperation, responsibility, shared understanding of common fate, interdependency, traditional sources of meaning - such as labour, family and identity are those values that need to be preserved and cherished.

A study conducted by Deloitte LLP demonstrates that high-performing companies hire candidates according to such criteria as work ethics, values, potential, experience and skills [3]. At the same time, the representatives of the Business Education Association of the USA and the OECD place self-management skills, i.e., ethical behaviour, prominently among the skills that influence organizations' success [4].

Generally, the employers' focus has shifted towards the so-called soft, purely human, skills. One of the reasons behind that is that those skills cannot be replaced with robots.

Respondents in a survey undertaken within a research by Global Human Capital Trends forecast a vast future demand for such skills as complex problem solving (63\%), cognitive abilities (55\%), social skills (52\%), as well as process skills (54\%) [5].

The ten most popular skills by 2020 are as follows, according to the World Economic Forum research: complex problem solving, critical thinking, creativity, people management, coordinating with others, emotional intelligence, judgment and decisionmaking, service orientation; negotiation; cognitive flexibility [6].

The authors of report "Skills in future. What you need to know and be able to in a new complex world" believe that the following knowledge and skills will be the most sought-for in a new reality: emotional literacy, empathy; ability to co-create, to sincerely and dedicatedly serve the others; systemic thinking; ability to focus and maintain attention; ability to realize a set of future scenarios, to create individual and collective future strategies; ability to self-(educate); cross-culturalism; ecological thinking [7, p. 72-75].

Whilst the research listed above basically relied on expert - including employer surveys, the following list of skill groups is compiled by the specialists of NTI University "20.35" based on an analysis of competence models of 50 leading companies from various economic spheres, taking into account that the results were processed by NLP (natural language processing) method. Based on the interviews with company employees and on the analysis of competence models 211 competences were identified and nine competencebased units were determined: value-based-regulatory; self-regulation; human interaction; thinking; work with systems and processes; work with innovation and changes, communication; work with information; entrepreneurship [8].

As we can see from the above - and this is the second trend - the complication of requirements to new-economy workers can be observed. If different research is supplemented, generalized and systematized [1-8], one may single out the following groups of qualities and skills relevant for new-economy workers:

1. Personal (in our opinion, they constitute a systemically important nucleus upon which the line of application of other qualities and skills is dependent - either for the benefit or to the detriment of the development of man, society and economy), etc.

1.1 value-based-conceptual (to understand the outside world; to find one's way around it, to understand the values of good and evil, to realize one's role and mission, to be able to 
choose target-based and concept-based objectives for one's actions, to make decisions);

1.2 value-based-regulatory (honesty, trustworthiness, work ethics, responsibility, reliability, discipline, decisiveness, self-management, adaptability, initiative, etc.);

1.3. those targeted at self-improvement (mastering methods of spiritual, intellectual, physical self-development, emotional self-regulation, self-support, etc.);

1.4 inter-cultural (ability to live with people from different cultures and religions);

2. Cognitive, such as:

2.1. memory, thinking agility, ability to concentrate and manage attention;

2.2. logical, analytical, critical thinking, research skills, including those in the field of inter-disciplinary research; cognitive flexibility;

2.3. ability to use information, ability to learn throughout life and to apply academic knowledge to achieve results in professional activities;

3. Creative (we have identified them as a separate group, apart from cognitive ones, as they are synthetic in nature and are significant), including, being inspired, able to generate ideas, being prognostic, critical, having one's own viewpoint, understanding inconsistencies; ability to unconventionally resolve complex and multi-faceted problems;

4. Socio-behavioural (action-related-emotional):

4.1 goal-setting; goal achievement, reflexive thinking, self-assessment;

4.2 empathy, ability to co-create and to serve the others with sincerity and dedication; communicative skills (methods of interaction with the others and with distant events and people; skills to work in a team, etc.)

5. Digital: 5.1 basic skills (ability to use a computer and Internet to resolve general tasks); 5.2 ability to use information technologies (understanding their application, strengths and weaknesses, ability to critically interpret information); ability to process large data arrays and to make judgments on that basis, to track trends and interrelations; 5.3 skills to learn online; 5.4 programming skills, IT literacy, ability to work with machine intelligence, algorithms (most often, those skills are professional).

6. Professional - skills relevant for a chosen professional sphere.

Therefore, a new-economy worker should have diversified qualities and skills. However, in practice we can observe an inconsistency between the actual and the requisite skills of potential workers that tells on a demand for them at the labor market. Some of employers and experts have begun to realize the problem. In one of the surveys $44 \%$ employers noted that the filling out of recruitment ad forms is hampered by the lack of such a communication skill. Thirty-three per cent told that the absence of personal skills (honesty, responsibility, teamwork, adaptability) at a workplace proved to be the most significant obstacle for meeting the employers' needs [9].

In a survey by LinkedIn, 58\% recruitment managers say that lack of cognitive skills in employees restricts their company's efficiency, whereas $89 \%$ of the management surveyed by Wall Street Journal say that they experience «very serious » or «certain » difficulties trying to find candidates who possess such skills [9].

Other research and surveys have detected significant gaps in the critical thinking skills and in the skills to apply academic knowledge [9].

Of peculiar concern is the fact that a new generation, a product of the digital revolution, is joining the labour market. A rapid upsurge of information - including digital technologies was seen in the late 1990s and continues to this day. That, alongside cultural changes in the society, globalization processes and a roller coaster of economic crises, has had a significant impact upon a socio-psychological portrait of a new generation born at the time. U. Strauss and N. Howe, the authors of the known generational theory, called it a digital generation. In year or two, the representatives of that generation will make up 20 per cent of the global workforce.

But what are the qualities and skills developed under the influence of information 
technologies, education and society's culture in the contemporary young people who are about to join the new economy and be competitive at the labour market?

As evidenced by many studies of the digital-generation, human psyche is now undergoing dramatic changes as a result of the influence of digital technologies and contemporary culture: a degradation of the natural intelligence is taking place, the sensuous and volitional sphere of human psyche is being damaged, and values have been changing.

At the level of personal qualities and skills this is manifested by the development of an inadequate perception of the world, the borrowing of values and needs from digital templates, a blurred system of values and lack of consistent preferences, moral relativism, egocentricity and individualism, hedonism, self-confidence and a strive for comfort [10,11].

At the level of cognitive and creative qualities and skills this is manifested in low and short-time focus of attention, intellectual dependence on technology (outsourcing the function of memory to gadgets), and, hence, shallow and short-time memory, reduction in analytical abilities and ability to think critically; development of "clip thinking" which is characterized by fragmentary and superficial nature [10, 12-14].

At the level of socio-behavioural (action-related - emotional) qualities and skills this is manifested in the elimination of a border between reality and illusion; an abrupt drop in an ability of social interaction, sympathy, self-control, including, of goal-setting, in the lack of tolerance (a strive for having it all and at once), in the perception of difficulties as a token of a wrongly chosen path $[10,11,15]$.

So, the gaps in the requisite and real qualities of potential new-economy workers do exist. Overcoming them is a highly challenging task that requires, first and foremost, for the focus of the entire policy - governmental and corporate, technological and economic - to be shifted towards a man. It means that all innovations, governmental and corporate programs should be assessed in line with the humane and social utility criteria. Moreover, the educational system also requires to undergo essential changes.

In May 2017, Pew Research Center published the results of an expert survey "The Future of Jobs and Jobs Training", in which experts had assessed, among the other things, the readiness and perspectives of a contemporary system of education to those challenges which are connected with the changes in the labour sector triggered by the technical revolution [16]. Expert opinions over the future educational models were divided, of which two groups may be identified that embody contrary positions.

The first group is critical of the traditional educational system and comes forward with revolutionary changes involving a transition to digital technology and to online educational pattern. This approach relies on the opinion that knowledge and skill acquisition demands little human interaction and that, therefore, a half or more of the knowledge and skills may be developed through self-education with the help of digital technologies.

The second group - which is of the opinion that the authors of this publication share believes that the classical system (with values, skills and knowledge being passed from man to man) which develops a nucleus of values and rules within a man, which teaches and develops personal, social, cognitive skills and gives fundamental knowledge and, in part, professional knowledge as well, should remain the pillar of the new educational model.

During the period of rapid technological development not only new opportunities arise for economy and society, but great risks also. That is why it is necessary to understand that the development and application of technologies is based on a particular system of values focusing either on a harmonious development of man and society, or on the realization of authoritative and economic interests of certain groups, contrary to and at the expense of the degradation and exploitation of the others. That is why a key issue of education is creation, support and development of the value- and sense-based personality nucleus, its spiritual and moral world, and, in terms of a country as a whole - formation and development of moral and intellectual potential of the society, of the society's moral and intellectual elite. These 
will form the basis upon which it may be possible to exercise consistent, innovative, socially beneficial, humane and safe development of the socio-economic system.

Digital technologies in education are supplementary to traditional ones; they need to be fully realized at workplaces during the process of the lifelong training of an adult (fullyformed) person. The sphere, volume, kind of digital technologies used in classical education needs, in our opinion, to be determined by psychophysiological norms, age and state of health of children and young people.

At the same time, soft skills, which are expected to be in deficit, are only acquired through practicing interpersonal communication, humanitarian disciplines and practices. And this is the experience that a person acquires in a family, educational system and in the process of their participation in communities that facilitate versatile development of personality (culture, sport, public service). This is a sphere of persistent priority for a man. That is why the classical educational model needs to remain basic.

In general, the ability to implement opportunities which the new economy will yield under the influence of technological, demographic and environmental changes will depend on the effectiveness of the organization and functioning of lifelong educational systems [17, p.34]. The state, employers and educational structures need to participate in the creation and operation of those systems, yet the state needs to retain the governing role.

The funding of expenditure on education, including, that in the sphere of professional training, re-training and advanced training, remains a key issue. Public funding may support and encourage educational programs with the help of such tools as guaranteed financing, payment of allowances, creation of guarantees of the quality of professional training, opening individual educational accounts, provision of subsidies, grants, credits and tax benefits $[1$, p.5]. This needs to take into account shrinking possibilities of public funding due to the build-up of debts, socio-demographic problems and deterioration of macroeconomic situation in general. This calls for diversification of the sources of funding, in particular, for active involvement of employers.

Governments need to create appropriate mechanisms of public funding and of encouraging entrepreneurs to increase investments into professional training, advanced training and re-training. They also need to enhance decent work opportunities for young people via programs of employment and support of young entrepreneurship. Private sector is required to play a special role by offering appropriate quality apprenticeship and first jobs to young people [17, p.37]. Among the other things, industry-specific or national tax preferences could become mechanisms for the engagement of private sector to the funding of professional training.

\section{Conclusions}

Therefore, the strengthening of the new economy is accompanied by the changes of requirements to workers. In parallel, their real skills developed under the influence of information technologies and contemporary society's culture contradict those requirements generating gaps.

To overcome the existing situation and to ensure the development of man, society and new information technology-based economy systemic changes need to be implemented:

- in the educational and socio-economic policy of nation-states towards strengthening the state's regulatory role in the management of the socio-economic system, including, of the educational one, and in the regulation of the labour market;

- in educational models and in the entire educational system, in order to create a different value-motivational portrait of new generations and to adapt these models and system to abrupt and in-depth changes of the external environment;

- in the construction and strengthening of a multilateral dialogue between the state, 
employers (business sector), educational institutions and workers for the purposes of ensuring quality education and lifetime training.

\section{References}

1. Skills policies and systems for a future workforce. Issue Briefs No. 8. International Labour Organization, (2018), available online: https://www.ilo.org/global/topics /future-of-work/publications/issue-briefs/WCMS_618170/lang--en/index.htm

2. K. Schwab, The Fourth industrial revolution: transl. from Engl. ( "E", Moscow.: 2017).

3. From careers to experiences: new pathways 2018 Global Human Capital Trends https://www2.deloitte.com/insights/us/en/focus/human-capital-trends/2018/building21st-century-careers.html

4. National Business Education Association. This we believe about teaching the soft skills: human rlations, self-management, and workplace enhancement policy statement 67 https://www.nbea.org/newsite/curriculum/policy/no_67.pdf

5. AI, robotics, and automation: Put humans in the loop2018 Global Human Capital Trends https://www2.deloitte.com/insights/us/en/focus/human-capital-trends/2018/airobotics-intelligent-machines.html

6. A. Gray, The 10 skills you need to thrive in the Fourth Industrial Revolution. World Economic Forum, January 19, (2016), https:/www.weforum.org/agenda/2016/01/the10-skills-you-need-to-thrive-in-the-fourth-industrial-revolution/

7. Skills in future. What you need to know and be able to in a new complex world [Electronic resource]. - Access mode: https://worldskills.ru/media-czentr/dokladyi-iissledovaniya.html

8. Digital competences basic model is included into a curriculum https://www.comnews.ru/print?nid=118097

9. R. Stephens, Automate this: building the perfect 21st-century worker REPORT. Published April 7, (2017), https://www.thirdway.org/report/automate-this-building-theperfect-21st-century-worker

10. M. Spitzer, Anti-Brain: Digital technologies and brain [Electronic resource]. - Access mode: http://www.litres.ru/pages/ biblio_book/? art=6377279\& lfrom=202213444

11. S. Turkle, Life on the screen: identity in the age of the Internet (Simon and Schuster, New York, 1995)

12. Dr. N. Kardaras, Screens In Schools Are a $\$ 60$ Billion Hoax [Electronic resource]. Access mode: http://time.com/4474496/screens-schools-hoax/

13. V. L. Dunckley M.D., Gray matters: too much screen time damages the brain (2014) https://www.psychologytoday.com/us/blog/mental-wealth/201402/gray-matters-toomuch-screen-time-damages-the-brain

14. Interview Clifford Nass // Digital Nation. Life on the digital frontier. URL: http://www.pbs.org/wgbh/pages/frontline/digitalnation/interviews/nass.html

15. Stuart Wolpert, In our digital world, are young people losing the ability to read emotions? [Electronic resource]. - Access mode: https://www. universityofcalifornia.edu/news/are-young-people-losing-ability-read-emotions

16. R. Lee, J. Anderson, The Future of Jobs and Jobs Training. Pew Research Center, (2017), available online: http://www.pewinternet.org/2017/05/03/the-future-of-jobsand-jobs-training/

17. Work for a brighter future - Global Commission on the Future of Work International Labour ORGANIZATION https://www.ilo.org/wcmsp5/groups/public/---dgreports/--cabinet/documents/publication/wcms_662410.pdf 